\title{
The Expression of TNF $\alpha$, IL-6, IL-2 and IL-8 in the Serum of Patients with Idiopathic Sudden Sensorineural Hearing Loss: Possible Prognostic Factors of Response to Corticosteroid Treatment
}

\author{
Zinovia Tsinaslanidou $^{a}$ Miltiadis Tsaligopoulos ${ }^{b}$ Nikolaos Angouridakis ${ }^{a}$ \\ Victor Vital $^{b} \quad$ Georgios Kekes $^{a} \quad$ Jiannis Constantinidis ${ }^{a}$ \\ a 2 nd Department and ${ }^{b} 1$ st Department of Otolaryngology Head and Neck Surgery, \\ Aristotle University of Thessaloniki, Thessaloniki, Greece
}

\author{
Key Words \\ Sudden sensorineural hearing loss - Immunological theory - Proinflammatory cytokines . \\ TNF $\alpha \cdot$ IL- $6 \cdot$ IL-2 $\cdot$ IL-8 $\cdot$ Recovery
}

\section{Abstract}

Introduction: Idiopathic sudden sensorineural hearing loss (ISSNHL) remains one of the major unsolved otologic emergencies. A viral infection, a systemic inflammatory disorder, as well as physical, mental and metabolic stress can trigger an innate immune response in the inner ear resulting in ISSNHL. Proinflammatory cytokines play a central role in this cochlear immunological cascade. Objective: To examine the expression of proinflammatory cytokines in the serum of patients with ISSNHL in correlation with the therapeutic outcome of intravenous administration of corticosteroids. Method: Forty-three patients primarily diagnosed with ISSNHL underwent intravenous corticosteroid treatment for 8 days. The expression of tumor necrosis factor- $\alpha$ (TNF $\alpha$ ), interleukin-6 (IL-6), interleukin-2 (IL-2) and interleukin-8 (IL-8) was detected with the use of enzyme-linked immunosorbent assay in serum specimens on the 1st and 8th day of treatment and it was correlated with the treatment outcome. Results: TNF $\alpha$ reduction and IL- 6 increase strongly correlate with a good therapeutic result $\left[\chi^{2}(2)=13.12\right.$, $p=0.001$ and $\left.\chi^{2}(2)=16.78, p=0.0001\right]$. IL-8 increase reflects negatively on the outcome, however, not in a statistically significant way. No association was established between IL-2 variations and the therapeutic outcome. Conclusions: TNF $\alpha$ and IL- 6 can be used as prognostic factors for the treatment outcome, whereas the prognostic value of IL-8 requires further statistical confirmation. 


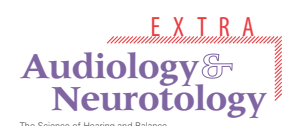

Audiology \begin{tabular}{l|l}
\hline Audiol Neurotol Extra 2016;6:9-19 \\
\hline DOI: 10.1159/000442016 & $\begin{array}{l}\text { ( ) 2016 The Author(s). Published by S. Karger AG, Basel } \\
\text { www.karger.com/aue }\end{array}$
\end{tabular}

Tsinaslanidou et al.: The Expression of TNF $\alpha$, IL-6, IL-2 and IL-8 in the Serum of

Patients with Idiopathic Sudden Sensorineural Hearing Loss

\section{Introduction}

Idiopathic sudden sensorineural hearing loss (ISSNHL) is defined as a 30-dB loss over 3 continuous frequencies occurring in less than 3 days [Chang et al., 2005]. It was first described by De Kleyn in 1944 [De Kleyn, 1944]. ISSNHL represents a disease entity of unknown etiology which is characterized by sudden onset, is unilateral in most cases and may sometimes reach the threshold of deafness [Rudack et al., 2004]. It shows equal sex distribution and mainly affects patients between the ages of 30 and 60 years [Yehudai et al., 2006]. According to the literature, the yearly incidence ranges from 5 to 20/100,000 inhabitants, depending on nationality. Interestingly, recent nationwide epidemiologic surveys in Europe, Asia and USA, have noted an increase of its incidence in the last decades, extending to the number of 160/100,000/year [Lopez-Gonzalez et al., 2012]. Moreover, ISSNHL has a severe impact on the patient's quality of life, causing not only physical disability but an additional psychological burden [Nakashima et al., 2000; Psifidis et al., 2006; Lee et al., 2010].

ISSNHL remains one of the major unsolved otologic emergencies. Its etiology, despite the number of surveys performed, still remains unclear. This is mainly because a direct investigation of labyrinthine tissue in a living patient is not yet possible without permanent damage of the inner ear and postmortem histopathology is rarely available. Therefore, animal models that mimic the disease entity have been developed, as well as indirect diagnostic tools, such as serologic testing for different agents, in order to unravel the pathogenesis of ISSNHL [Satoh et al., 2003; Bachor et al., 2005; Solares and Tuohy, 2005; Merchant et al., 2008].

The central nervous system, and the inner ear by extension, were originally thought to be immunoprivileged sites due to the presence of the blood-brain and the blood-labyrinthine barriers, respectively [Bodmer et al., 2002]. In 1958, Lehnhardt was the first to contradict the 'immunoprivileged site' theory about the inner ear. He reported a patient in whom progressive hearing loss in one ear became bilateral after a period of time, suggesting that degeneration of inner ear tissues in one ear led to the production of anti-cochlear antibodies that eventually damaged the other ear [Lehnhardt, 1958]. Further support to this assumption was derived from a seminal study by McCabe [1979] in which immunosuppressive therapy with corticosteroids and cyclophosphamide improved cases of sensorineural hearing loss. Nowadays, it has been confirmed that the cochlea is activated by systemic events which stimulate innate immunity and, when an antigen is present in the inner ear, a robust cochlear adaptive response is generated, possibly leading to the development of immune-mediated hearing loss [Hashimoto et al., 2005]. This cochlear immune response, resulting in ISSNHL, is regulated by a number of cytokines whose implication has been previously outlined in other types of sensorineural hearing loss, such as acoustic trauma and cisplatin-induced ototoxicity [So et al., 2008; Hwang et al., 2011; Kim et al., 2011].

The noted emphasis on the immune response within the inner ear as the cause of ISSNHL, in combination with the raise of the disease's incidence in the last decades, underline the importance of conducting experimental studies on this subject. Our goal is to investigate the expression of tumor necrosis factor- $\alpha$ (TNF $\alpha$ ), interleukin-6 (IL-6), interleukin-2 (IL-2) and interleukin-8 (IL-8) in the serum of patients with ISSNHL in correlation with the therapeutic result of corticosteroid intravenous administration. These proinflammatory cytokines are examined as possible prognostic factors for the disease entity and point out new perspectives regarding the development of novel therapeutic approaches. 


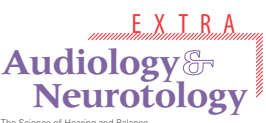

Table 1. Exclusion criteria

\begin{tabular}{l|l}
\hline Audiol Neurotol Extra 2016;6:9-19 \\
\hline DOI: $10.1159 / 000442016$ & $\begin{array}{l}\text { @ } 2016 \text { The Author(s). Published by S. Karger AG, Basel } \\
\text { www.karger.com/aue }\end{array}$ \\
\hline
\end{tabular}

Tsinaslanidou et al.: The Expression of TNF $\alpha$, IL-6, IL-2 and IL-8 in the Serum of Patients with Idiopathic Sudden Sensorineural Hearing Loss
Start of treatment $>5$ days after SSNHL

Medication for ISSNHL prior to admission

Congenital hearing loss

Ménière's disease

Family history of genetic hearing loss

Chronic or acute otitis media

Cholesteatoma or otosclerosis

History of prior ear surgery (except ventilating tubes)

History of trauma (head, acoustic, barotrauma)

History of luetic deafness

History of meningitis

History of autoimmune disease (SLE, rheumatoid arthritis, Sjögren's syndrome, Cogan's syndrome, Behcet's disease, etc.)

Oncologic history with recent chemotherapy or radiation

Prior use of ototoxic drugs

Neurological disorders/clinical depression

Abnormal MRI findings (lesions at the internal auditory meatus, the cerebellopontine angle, the brainstem)

Pregnancy

Acute or chronic infections

Systemic diseases that may increase the risk of adverse effects from intravenous steroid treatment (unregulated hypertension, unregulated diabetes mellitus, chronic renal/liver insufficiency, etc.)

\section{Materials and Methods}

Between May 2009 and October 2013, a prospective cohort study was conducted on 43 patients primarily diagnosed with ISSNHL, with the collaboration of the 1st and 2nd Department of Otolaryngology Head \& Neck Surgery, Aristotle University of Thessaloniki (AUTH). The patients were hospitalized in both departments. The study was approved by the local Ethics Committee of the AUTH Faculty of Medicine and was carried out in accordance with the Declaration of Helsinki of 1975, as revised in 2008. All patients were thoroughly informed about the clinical protocol and gave written consent.

All patients underwent intravenous treatment with corticosteroids (prednisone) for 8 days. The determination of the prednisone dosage was based on the patients' body weight and was tapered gradually during hospitalization. Beyond the 8-day period of intravenous treatment with corticosteroids, modifications of the therapeutic approach did not exclude the patient from the protocol.

Eligibility criteria included a sudden unilateral hearing loss of at least $30 \mathrm{~dB}$ over 3 continuous frequencies occurring in less than 3 days, with the start of treatment taking place within 5 days from the onset of hearing loss. No treatment (intravenous or oral medication) for ISSNHL was received prior to hospitalization. Patients admitted to our departments beyond 5 days from the onset of hearing loss as well as patients who had received medication for ISSNHL prior to their admission were excluded from the protocol. Additional exclusion criteria are listed in table 1. The diagnosis of ISSNHL was confirmed with a thorough otorhinolaryngological examination and standard audiometric evaluation. An extensive medical history report, including the patients' demographic facts as well as individual and family medical history, was filled out, with emphasis on smoking habits and alcohol consumption. A prerequisite for the diagnosis of ISSNHL is a normal magnetic resonance imaging (MRI). The imaging was conducted at least 3 months after the hearing loss, in order to protect the patient 
from exposure to intense noise close to the disease onset. Patients with abnormal MRI findings were retrospectively excluded from the protocol.

Two blood samples after venipuncture were received from each patient: one before and one at the end of treatment, on the 1st and 8th day, respectively. The choice of the specific days for the blood samples was made in accordance with the 8-day protocol of intravenous treatment with corticosteroids the two departments follow on ISSNHL. Plasma and serum were derived from the blood samples by centrifugation, which in turn were classified receiving serial codes and were stored in a deep freezer $\left(-74^{\circ} \mathrm{C}\right)$. In these serum specimens, the production of 4 proinflammatory cytokines, TNF $\alpha$, IL-6, IL-2 and IL-8, was detected with the use of enzyme-linked immunosorbent assay (ELISA).

A standard audiometric evaluation was performed for each patient prior to treatment, including air- and bone-conducted pure tone audiometry (PTA), Weber and Rinne tests and tympanometry curve with determination of acoustic reflexes. PTA of 500, 1,000, 2,000 and $4,000 \mathrm{~Hz}$, calculated as the arithmetic mean of hearing thresholds, was used to categorize the hearing losses as mild (26-40 dB), moderate (41-60 dB), severe (61-80 dB) and profound $(>80 \mathrm{~dB}$ ). In order to monitor the progression of hearing thresholds during the 8-day protocol of intravenous treatment with corticosteroids, successive audiometric tests were performed additionally on the 4th and 8th day of the protocol. The therapeutic result was estimated as the difference between the PTAs of the 1st and 8th day audiograms. Total recovery was defined as a complete restoration of normal hearing threshold (PTA $<25 \mathrm{~dB}$ ), whereas excellent recovery was determined as a PTA improvement of $\geq 30 \mathrm{~dB}$, partial recovery between $15-30 \mathrm{~dB}$ and lack of recovery $<15 \mathrm{~dB}$. In order to simplify statistical analysis, total and excellent recovery were united in one group under the title total/excellent recovery. It has to be noted that the diagnosis and monitoring of ISSNHL require further specialized neurotologic examination, such as distortion product otoacoustic emission and auditory brainstem response tests, which are not described in this article since their results were not included in our protocol. Finally, when the patients were to be discharged, the necessary follow-up was reassured.

The statistical analysis of the patients' data was performed with the use of SPSS 17.0 software [mean values, minimum and maximum values, and standard deviation (STD)], and Pearson's $\chi^{2}$ test of independence was used in order to correlate the variations (increase or reduction) of each cytokine with the therapeutic outcome.

\section{Results}

Between May 2009 and October 2013, 43 patients primarily diagnosed with ISSNHL were included in our study. The mean age of the patients was 53 years (range 13-79). The baseline characteristics of the study population are displayed in table 2 . One patient relapsed after treatment (2.3\%) and was excluded from further statistical analysis. This patient will be examined as a case study.

Mild sensorineural hearing loss was observed in $7.2 \%$ of the patients, moderate in $19 \%$ and severe in $28.6 \%$, and $45.2 \%$ of the patients presented with profound hearing loss. Total/ excellent recovery was seen in 15 patients (35.7\%), partial recovery in $6(14.3 \%)$ and lack of recovery was noted in $21(50 \%)$.

TNF $\alpha$, IL-6, IL-2 and IL-8 were detected in serum specimens received from each patient on the 1st and 8th day of treatment with the use of ELISA. The mean of each cytokine's expression was estimated, with concurrent determination of STD, minimum and maximum values, separately for each group of patients in correlation with their response to treatment. The expression of TNF $\alpha$, IL-6, IL-2, IL-8 on the 1st and 8th day is presented in tables 3 and 4. 


\section{Audiology \\ Neurotology}

Table 2. Baseline characteristics of the study population

\begin{tabular}{|c|c|c|}
\hline \multicolumn{3}{|c|}{ Audiol Neurotol Extra 2016;6:9-19 } \\
\hline DOI: $10.1159 / 000442016$ & \multicolumn{2}{|c|}{$\begin{array}{l}\text { (c) } 2016 \text { The Author(s). Published by S. Karger AG, Basel } \\
\text { www.karger.com/aue }\end{array}$} \\
\hline \multicolumn{3}{|c|}{$\begin{array}{l}\text { Tsinaslanidou et al.: The Expression of TNF } \alpha \text {, IL-6, IL-2 and IL-8 in the Serum of } \\
\text { Patients with Idiopathic Sudden Sensorineural Hearing Loss }\end{array}$} \\
\hline \multicolumn{3}{|l|}{ Age, years } \\
\hline Mean & & 53 \\
\hline Range & & $13-79$ \\
\hline \multicolumn{3}{|l|}{ Sex } \\
\hline Male & & $16(37.2 \%)$ \\
\hline Female & & $27(62.8 \%)$ \\
\hline \multicolumn{3}{|l|}{ Affected ear } \\
\hline Right & & $22(51.2 \%)$ \\
\hline Left & & $21(48.8 \%)$ \\
\hline \multicolumn{3}{|l|}{ Smoking habits } \\
\hline Nonsmoker & & $18(41.9 \%)$ \\
\hline Mild-to-moderate s & ker & $16(37.2 \%)$ \\
\hline Heavy smoker & & $3(7 \%)$ \\
\hline Ex-smoker & & $1(2.3 \%)$ \\
\hline Passive smoker & & $5(11.6 \%)$ \\
\hline \multicolumn{3}{|l|}{ Alcohol consumption } \\
\hline None & & $20(46.6 \%)$ \\
\hline Moderate $(<2$ units & eek) & $21(48.8 \%)$ \\
\hline Elevated ( $>2$ units & ek) & $1(2.3 \%)$ \\
\hline Alcoholism $(>2$ uni & day) & $1(2.3 \%)$ \\
\hline \multicolumn{3}{|c|}{ Days of SSNHL onset prior to treatment } \\
\hline $0-1$ & & $19(45.2 \%)$ \\
\hline $2-3$ & & $11(26.2 \%)$ \\
\hline $4-5$ & & $12(28.6 \%)$ \\
\hline
\end{tabular}

Table 3. TNF $\alpha$ and IL-6 expression on the 1st and 8th day in correlation with the therapeutic result

\begin{tabular}{|c|c|c|c|c|c|c|}
\hline & \multicolumn{2}{|c|}{$\begin{array}{l}\text { Total/excellent } \\
\text { recovery }\end{array}$} & \multicolumn{2}{|c|}{$\begin{array}{l}\text { Partial } \\
\text { recovery }\end{array}$} & \multicolumn{2}{|c|}{$\begin{array}{l}\text { Lack of } \\
\text { recovery }\end{array}$} \\
\hline & $\mathrm{TNF} \alpha$ & IL-6 & $\mathrm{TNF} \alpha$ & IL-6 & $\mathrm{TNF} \alpha$ & IL-6 \\
\hline \multicolumn{7}{|l|}{ 1st day } \\
\hline Mean & 171.9 & 1.5 & 219.9 & 1.5 & 110.7 & 2.6 \\
\hline STD & 278.0 & 1.1 & 194.6 & 0.6 & 275.4 & 2.9 \\
\hline Min. & 6.3 & 0.4 & 5.7 & 0.8 & 5.9 & 0.4 \\
\hline Max. & 846.0 & 4.3 & 469.9 & 2.4 & 941.1 & 10.1 \\
\hline \multicolumn{7}{|l|}{ 8th day } \\
\hline Mean & 45.5 & 1.9 & 141.2 & 1.7 & 64.2 & 1.7 \\
\hline STD & 52.1 & 1.3 & 138.8 & 0.4 & 154.0 & 1.8 \\
\hline Min. & 5.1 & 0.6 & 5.5 & 1.2 & 4.9 & 0.3 \\
\hline Max. & 150.3 & 4.8 & 337.8 & 2.2 & 533.3 & 6.8 \\
\hline
\end{tabular}

Additionally, we calculated the variation of each cytokine's expression between the 1st and 8th day, in order to evaluate a possible correlation with the therapeutic result. As shown in table 5, the downregulation of TNF $\alpha$ and the upregulation of IL-6 appear to correlate with a positive response to treatment, the increase of IL-8 expression is associated with poor therapeutic outcome, whereas no specific pattern can be seen in the variation of IL-2 expression between the 1st and 8th day in correlation with treatment outcome.

Due to the great range of the cytokine values, we investigated the increase or reduction of TNF $\alpha$, IL-6, IL-2 and IL-8, as qualitative variables, in correlation with the therapeutic outcome using Pearson's $\chi^{2}$ test of independence (table 6). TNF $\alpha$ reduction between the 1 st and 8th day of treatment is a positive prognostic factor in patients with SSNHL, as it is strongly associated with a good therapeutic outcome $\left[\chi^{2}(2)=13.12, p=0.001\right]$. Additionally, IL-6 


\section{Audiology \\ Neurotology}

Table 4. IL-2 and IL-8 expression on the 1 st and 8 th day in correlation with the therapeutic result

Table 5. Variation of cytokines between the 1 st and 8 th day

\begin{tabular}{l|l}
\hline Audiol Neurotol Extra 2016;6:9-19 \\
\hline DOI: 10.1159/000442016 & $\begin{array}{l}\text { @ 2016 The Author(s). Published by S. Karger AG, Basel } \\
\text { www.karger.com/aue }\end{array}$
\end{tabular}

Tsinaslanidou et al.: The Expression of TNF $\alpha$, IL-6, IL-2 and IL-8 in the Serum of Patients with Idiopathic Sudden Sensorineural Hearing Loss

\begin{tabular}{|c|c|c|c|c|c|c|}
\hline & \multicolumn{2}{|c|}{$\begin{array}{l}\text { Total/excellent } \\
\text { recovery }\end{array}$} & \multicolumn{2}{|c|}{$\begin{array}{l}\text { Partial } \\
\text { recovery }\end{array}$} & \multicolumn{2}{|c|}{$\begin{array}{l}\text { Lack of } \\
\text { recovery }\end{array}$} \\
\hline & IL-2 & IL-8 & IL-2 & IL-8 & IL-2 & IL-8 \\
\hline \multicolumn{7}{|l|}{ 1st day } \\
\hline Mean & 39.2 & 6.7 & 12.6 & 2.6 & 28.3 & 9.7 \\
\hline STD & 61.4 & 6.1 & 13.5 & 1.6 & 63.6 & 6.4 \\
\hline Min. & 1.0 & 0.2 & 2.8 & 0.1 & 1.9 & 0.2 \\
\hline Max. & 208.2 & 20.7 & 35.4 & 4.4 & 237.3 & 23.3 \\
\hline \multicolumn{7}{|l|}{ 8th day } \\
\hline Mean & 35.9 & 13.4 & 10.6 & 9.4 & 13.1 & 15.7 \\
\hline STD & 58.3 & 16.4 & 8.7 & 10.7 & 23.5 & 18.4 \\
\hline Min. & 0.5 & 0.2 & 3.1 & 0.2 & 2.0 & 0.1 \\
\hline Max. & 197.2 & 48.4 & 26.6 & 23.8 & 97.5 & 58.1 \\
\hline
\end{tabular}

\begin{tabular}{lrrrl}
\hline & TNF $\alpha$ & IL-6 & \multicolumn{1}{l}{ IL-2 } & \multicolumn{1}{l}{ IL-8 } \\
\hline Total/excellent recovery & $39.6 \%$ & $-49.8 \%$ & $11.7 \%$ & $-123.3 \%$ \\
Partial recovery & $27.2 \%$ & $-17.3 \%$ & $-11.5 \%$ & $-400.7 \%$ \\
Lack of recovery & $4.1 \%$ & $15.4 \%$ & $16.3 \%$ & $-629.9 \%$ \\
\hline
\end{tabular}

Mean values are shown. Variation $=($ day $1-$ day 8$) /$ day $1 \times 100 \%$.

Table 6. Reduction/increase of TNF $\alpha$, IL-6, IL-2 and IL-8 in correlation with the therapeutic outcome

\begin{tabular}{|c|c|c|c|c|c|c|c|c|}
\hline & \multicolumn{2}{|l|}{$\mathrm{TNF} \alpha$} & \multicolumn{2}{|l|}{ IL-6 } & \multicolumn{2}{|l|}{ IL-2 } & \multicolumn{2}{|l|}{ IL-8 } \\
\hline & red. & incr. & red. & incr. & red. & incr. & red. & incr. \\
\hline Total/excellent recovery & $15(100)$ & $0(0)$ & $4(26.7)$ & $11(73.3)$ & $9(60)$ & $6(40)$ & $6(40)$ & $9(60)$ \\
\hline Partial recovery & $6(100)$ & $0(0)$ & $2(33.3)$ & $4(66.7)$ & $2(33.3)$ & $4(66.7)$ & $2(33.3)$ & $4(66.7)$ \\
\hline Lack of recovery & $11(52.4)$ & $10(47.6)$ & $19(90.5)$ & $2(9.5)$ & $14(66.7)$ & $7(33.3)$ & 13 (61.9) & $8(38.1)$ \\
\hline Pearson's $\chi^{2}$ value & 13.125 & & 16.780 & & 2.154 & & 2.457 & \\
\hline $\mathrm{p}$ value & 0.001 & & 0.0001 & & 0.341 & & 0.293 & \\
\hline
\end{tabular}

Values are expressed as $\mathrm{n}(\%)$. red. = Reduction; incr. $=$ increase.

increase is a positive prognostic factor, showing strong correlation with good response to ISSNHL treatment with intravenous administration of corticosteroids $\left[\chi^{2}(2)=16.78, p=\right.$ $0.0001]$. On the other hand, the variations of both IL-8 and IL-2 do not have a statistically significant influence on the outcome of the treatment.

\section{Discussion}

Nowadays, the inner ear is no longer considered to be an immunoprivileged site despite the presence of the blood-labyrinthine barrier. This fact was first supported by Lehnhardt's report, followed by the results of McCabe's seminal study [Lehnhardt, 1958; McCabe, 1979]. Animal models of ISSNHL have demonstrated the trafficking of lymphocytes from the systemic 
circulation into the inner ear, elucidating the absence of a strict anatomical barrier within the cochlea [Vambutas et al., 2009]. Two routes are assumed for the infiltration of inflammatory cells in the cochlea: one is through the spiral modiolar vein from the systemic circulation and the other is from the endolymphatic sac where inflammatory cells are locally produced [Yoshida et al., 1999].

A viral infection, a systemic inflammatory disorder and physical, mental and metabolic stress can trigger an innate immune response with production of circulating ligands such as cytokines or reactive oxygen species within the inner ear [Merchant et al., 2008]. This immunological cascade accounts for the breakdown of tight junctions between stria vascularis endothelial cells, and consequently for the disruption of the blood-labyrinth barrier, leading to degeneration of the organ of Corti, stria vascularis and spiral ganglion, resulting in ISSNHL [Garcia Berrocal and Ramirez-Camacho, 2002]. The cochlear immune response can be activated transiently, explaining the spontaneous recovery of ISSNHL in many cases, whereas a prolonged activation would lead to an irreversible damage [Ferri et al., 2012]. Cytokines and adhesion molecules play a central role in the immune response in all mammalian tissues, including the inner ear [Yoshida et al., 1999]. Therapeutic approaches that target the secretion of these molecules can suppress inflammation and restrict the tissue damage, providing a prophylactic or therapeutic effect in cases of ISSNHL.

The expression of TNF $\alpha$ has been the subject in a number of research protocols on the pathogenesis of ISSNHL. TNF $\alpha$ is a proinflammatory cytokine that is secreted by activated macrophages, T cells, B cells and fibrocytes, inducing infiltration of the immunocompetent cells into the tissues and amplifying the immune response [Van Wijk et al., 2006]. TNF $\alpha$ postulates as a first messenger for primary immune cells, increases the expression of human leukocyte antigens and high-affinity IL-2 receptors and exerts multiple stimulatory effects on $\mathrm{T}$ cells by binding to specific receptors [Akdeniz et al., 2004]. In hair cells, TNF $\alpha$ plays its role via two receptors: the combination of TNF $\alpha$ with TNF receptor 1 (p53 protein) induces apoptosis, whereas its combination with TNF receptor 2 (p75 protein) activates Jun N-terminal kinases (JNK) and nuclear factor-kappaB (NF- $\mathrm{KB}$ ) which function as antiapoptotic agents [Zou et al., 2005]. So far, TNF $\alpha$ has been implicated in the pathophysiology of different types of sensorineural hearing loss, i.e. in SNHL postbacterial meningitis or in SNHL due to ototoxic drugs [Aminpour et al., 2005; So et al., 2008; Kim et al., 2011]. In cisplatin-induced hearing loss, TNF $\alpha$ activates NF- $\kappa$ B, MAPKs and STAT pathways, which, in turn enhance its expression, resulting in inner ear degeneration and manifestation of SNHL. It is possible that in a similar way, TNF $\alpha$ production may lead to apoptosis of inner ear cells in ISSNHL. Moreover, recent studies have demonstrated that TNF $\alpha$ is implicated in the pathogenesis of ISSNHL via activation of the sphingosine-1-phosphate (S1P) signaling pathway, through which it induces a proconstrictive state at the cochlear microcirculation [Scherer et al., 2010]. This fact underlines the possible implication of a proinflammatory cytokine, not only in the immune-mediated hearing loss, but additionally in ISSNHL that results from vascular occlusion.

In our study, we demonstrated that TNF $\alpha$ reduction between the 1st and 8th day of intravenous corticosteroid administration is associated with hearing restoration. Our result supports the study by Demirhan et al. [2013] which showed that TNF $\alpha$ posttreatment values are elevated in the treatment nonresponders and complies with both clinical trials and case reports in the literature that favor the use of TNF $\alpha$ inhibitors in the treatment of ISSNHL [Staecker and Lefebvre, 2002; Satoh et al., 2002, 2003; Van Wijk et al., 2006; Demirhan et al., 2013]. With the exception of our study and the one recently published by Demirhan et al., the variation of TNF $\alpha$ expression has not been evaluated in other research protocols. Ren et al. [1998] showed that plasma levels of TNF $\alpha$ and IL-6 in patients with ISSNHL were significantly higher and Voronkin et al. [1999] revealed a more active production of TNF $\alpha$ in the supernatant of cultivated mononuclears from patients with ISSNHL compared to the control group, 
whereas there is one study showing lower TNF $\alpha$ titters in ISSNHL [Suslu et al., 2009]. The expression of TNF $\alpha$ has been outlined as a possible prognostic factor of the response to corticosteroid treatment in ISSNHL and, additionally, as a promising target for novel therapeutic approaches.

IL-6, a well-known mediator of acute inflammatory reactions, is also upregulated in the early phases of a cochlear inflammatory response. Despite the fact that IL- 6 expression at the early stages of cochlear inflammatory response is lower than that of TNF $\alpha$ and IL-1 $\beta$, its implication in ISSNHL is critical [Yoshida et al., 1999; Fujioka et al., 2006]. IL-6 is known to act as a proliferation factor of B cells or plasma cells, resulting in antibody production locally as an antioxidative agent by inducing antiapoptotic gene expression, including the bcl gene family, and moreover, it has been implicated in the atherogenic process [Akdeniz et al., 2004; Fujioka et al., 2006; Cadoni et al., 2014]. In the inner ear, IL-6 expression is observed in the spiral ligament, the stria vascularis and the spiral ganglion neurons [Fujioka et al., 2006].

In a number of different types of sensorineural hearing loss, researchers have outlined the implication of IL-6. In the noise-damaged mice cochlea, blockade of IL-6 signaling suppressed inflammation and resulted in hearing restoration [Wakabayashi et al., 2010]. In cisplatin-induced hearing loss, IL-6 is implicated via STAT3 and NF- $\mathrm{\kappa B}$ activation, routes that can also be involved in the pathogenesis of ISSNHL [Kim et al., 2011]. Additionally, different types of systemic stress can converge at NKCA reduction, IL- 6 upregulation and neutrophil count increase, inducing sensorineural hearing loss via pathological activation of NF- $\mathrm{BB}$ cellular pathway [Masuda et al., 2012]. In ISSNHL, 174G/G and the C-572G polymorphisms of the IL- 6 gene are significantly associated with a higher risk of hearing loss due to vascular occlusion [Hiramatsu et al., 2012; Cadoni et al., 2014]. On the other hand, a case control study revealed no difference between IL-6 levels in patients with ISSNHL compared to the control group [Haubner et al., 2011]. Our study outlines a statistically significant positive correlation of IL-6 increase during intravenous corticosteroid treatment and hearing restoration. This result implies a possible antiapoptotic/antioxidative effect of IL-6 during the inner ear immune response. It is possible that IL-6 elevation can induce antiapoptotic genes' expression, for example the bcl family genes, leading to restoration of hair cell function, and consequently, recovery in cases of ISSNHL.

Besides TNF $\alpha$ and IL- 6 that are produced at the early stages of cochlear inflammatory response, there is a number of cytokines, such as IL-2 and IL-8, induced in later stages. IL-2 emanates from the endolymphatic sac, regulating the expression of SICAM-1, which, in turn, changes the characteristics of the spiral modiolar vein. Thus, IL-2 allows immune cells from the circulation to access the inner ear, leading to the formation of fibro-osseous matrix, ultimately resulting in the degeneration of the inner ear and consequently ISSNHL [Garcia Berrocal and Ramirez-Camacho, 2000, 2002]. However, the damage caused by the expression of IL-2 was shown to be reversible [Kubo et al., 1998]. Unfortunately, our study could not reveal a pattern between the variations of IL-2 during ISSNHL treatment and the disease outcome. On the other hand, our results show that the increase of IL-8 during treatment correlates with poor therapeutic outcome in ISSNHL, although this correlation is of no statistical significance. IL-8 is expressed in cultured spiral ligament fibrocytes after stimulation by TNF $\alpha$ and IL-1 $\beta$ [Yoshida et al., 1999]. In vivo, the interactions of leukocytes with endothelial cells induce IL-8, which in turn influences the infiltration of inflammatory cells and the maintenance of the immune response [Lukacs et al., 1995]. The installation of IL-8 in the middle ear cavity can affect inner ear function by accumulation of inflammatory cells, although the organ of Corti and the stria vascularis appeared to be intact [Iguchi and Anniko, 1998]. These data suggest a possible implication of IL-8 in the pathogenesis of ISSNHL. However, Haubner et al. [2011] failed to prove significantly different levels of IL-6 and IL-8 comparing patients with ISSNHL and healthy controls. The lack of statistical significance in the correlation 
between IL-8 variations and the therapeutic outcome can be attributed to the number of patients included in our study. It is possible that an increased number of patients in future studies would confirm the correlation and enhance its statistical significance.

\section{Conclusions}

It is obvious that different pathways are involved in the pathogenesis of ISSNHL, many of which intersect, underlining the complexity of this disease. At present time, the direct evaluation of the cellular responses in the inner ear is impossible. However, the development of animal models that mimic the disease entity, as well as indirect diagnostic tools, such as serologic testing for different agents, can be used to unravel its pathogenesis. Over the last decades, the attention was drawn to the implication of proinflammatory cytokines in the pathophysiology of ISSNHL. Prior to our study, the variation of cytokine expression in patients with ISSNHL has not been examined in correlation with the therapeutic result of intravenous corticosteroid administration, with the exception of the study by Demirhan et al. [2013] in which only the variations of TNF $\alpha$ expression were examined. Our study elucidates that there is a strong correlation between a positive therapeutic result and a TNF $\alpha$ reduction or an IL-6 increase. Thus, TNF $\alpha$ and IL- 6 can be used as prognostic factors for the treatment outcome. Additionally, IL-8 increase reflects negatively on the therapeutic result, implying a negative prognostic value, which was not confirmed as statistically significant. The implication of proinflammatory cytokines in the ISSNHL pathophysiology renders them targets for new therapeutic approaches. Future studies on the evaluation of systemic stress and the measurement of inflammatory biomarkers in patients with ISSNHL must be designed in order to achieve better insight on its pathophysiology. These studies are expected to outline new targets for therapeutic approaches and unravel novel prognostic factors, thus contributing in the development of more effective therapeutic strategies.

\section{Disclosure Statement}

The authors have no conflicts of interest to declare.

\section{References}

Akdeniz N, Esrefoglu M, Keles MS, Karakuzu A, Atasoy M: Serum interleukin-2, interleukin-6, tumor necrosis-alpha levels in patients with Behcet's disease. Ann Acad Med Singapore 2004;33:596-599.

Aminpour S, Tinling SP, Brodie HA: Role of tumor necrosis factor-alpha in sensorineural hearing loss after bacterial meningitis. Otol Neurotol 2005;26:602-609.

- Bachor E, Kremmer S, Kreuzfelder E, Jahnke K, Seidahmadi S: Antiphospholipid antibodies in patients with sensorineural hearing loss. Eur Arch Otorhinolaryngol 2005;262:622-626.

Bodmer D, Brors D, Pak K, Keithley EM, Mullen L, Ryan A et al: Inflammatory signals increase Fas ligand expression by inner ear cells. J Neuroimmunol 2002;129:10-17.

Cadoni G, Gaetani E, Picciotti PM, Arzani D, Quarta M, Giannantonio S, Paludetti G, Boccia S: A case-control study on proinflammatory genetic polymorphisms on sudden sensorineural hearing loss. Laryngoscope 2014;125: 28-32.

-Chang NC, Ho KY, Kuo WR: Audiometric patterns and prognosis in sudden sensorineural hearing loss in Southern Taiwan. Otolaryngol Head Neck Surg 2005;133:916-922.

De Kleyn A: Sudden complete or partial loss of function of the octavas system in apparently normal persons. Acta Otolaryngol 1944;32:407-429.

Demirhan E, Eskut NP, Zorlu Y, Cukurova I, Tuna G, Kirkali FG: Blood levels of TNF $\alpha$, IL-10 and IL-12 in idiopathic sudden sensorineural hearing loss. Laryngoscope 2013;123:1778-1781. 


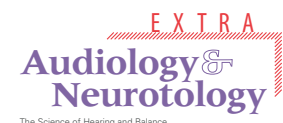

\begin{tabular}{l|l}
\hline Audiol Neurotol Extra 2016;6:9-19 \\
\hline DOI: 10.1159/000442016 & $\begin{array}{l}\text { C } 2016 \text { The Author(s). Published by S. Karger AG, Basel } \\
\text { www.karger.com/aue }\end{array}$ \\
\hline
\end{tabular}

Tsinaslanidou et al.: The Expression of TNF $\alpha$, IL- 6 , IL-2 and IL-8 in the Serum of

Patients with Idiopathic Sudden Sensorineural Hearing Loss

- Ferri E, Frisina A, Fasson AC, Armato E, Spinato G, Amadori M: Intratympanic steroid treatment for idiopathic sudden sensorineural hearing loss after failure of intravenous therapy. International scholarly research network. ISRN Otolaryngol 2012;2012:647271.

-Fujioka M, Kanzaki S, Okano HJ, Masuda M, Ogawa K, Okano H: Proinflammatory cytokines expression in noiseinduced damaged cochlea. J Neurosci Res 2006;83:575-583.

Garcia Berrocal JR, Ramirez-Camacho R: Immune response and immunopathology of the inner ear: an update. J Laryngol Otol 2000;114:101-107.

Garcia Berrocal JR, Ramirez-Camacho R: Sudden sensorineural hearing loss: supporting the immunologic theory. Ann Otol Rhinol Laryngol 2002;111:989-997.

Hashimoto S, Billings P, Harris JP, Firestein GS, Keithley EM: Innate immunity contributes to cochlear adaptive immune responses. Audiol Neurootol 2005;10:35-43.

Haubner F, Martin L, Steffens T, Strutz J, Kleinjung T: The role of soluble adhesion molecules and cytokines in sudden sensorineural hearing loss. Otolaryngol Head Neck Surg 2011;144:575-580.

-Hiramatsu M, Teranishi M, Uchida Y, et al: Polymorphisms in gene involved in inflammatory pathways in patients with sudden sensorineural hearing loss. J Neurogenet 2012;26:387-396.

-Hwang JH, Chen JC, Yang SY, Wang MF, Chan YC: Expression of tumor necrosis factor-a and interleukin-1b genes in the cochlea and inferior colliculus in salicylate-induced tinnitus. J Neuroinflammation 2011;8:30.

Iguchi H, Anniko M: Interleukin 8 can affect inner ear function. ORL J Otorhinolaryngol Relat Spec 1998;60:181189.

Kim HJ, Oh GS, Lee JH, Lyu AR, Ji HM, Lee SH, et al: Cisplatin ototoxicity involves cytokines and STAT6 signaling network. Cell Res 2011;21:944-956.

Kubo T, et al: Interleukin-2 affects cochlear function gradually but reversibly. ORL J Otorhinolaryngol Relat Spec 1998;60:272-277.

Lee JD, Park MK, Park KH, Lee BD: Intratympanic steroids in severe to profound sudden sensorineural hearing loss as salvage treatment. Clin Exp Otorhinolaryngol 2010;3:122-125.

Lehnhardt E: Plötzliche Hörstörungen auf beiden Seiten gleichzeitig oder nacheinander aufgetreten. Z Laryngol Rhinol Otol 1958;37:1-16.

Lopez-Gonzalez MA, Abrante A, Lopez-Lorente C, Gomez A, Dominguez E, Esteban F: Acute-phase inflammatory response in idiopathic sudden deafness: pathogenic implications. Int J Otolaryngol 2012;2012:216592.

Lukacs NW, Strieter RM, Elner V, Evanoff HL, Burdick MD, Kunkel SL: Production of chemokines, interleukin-8 and monocyte chemoattractant protein-1 during monocyte: endothelial cell interaction. Blood 1995;86:27672773.

Masuda M, Kanzaki S, Minami S, Kikuchi J, Kanzaki J, Sato H, et al: Correlations of inflammatory biomarkers with the onset and prognosis of idiopathic sudden sensorineural hearing loss. Otol Neurotol 2012;33:1142-1150.

McCabe BF: Autoimmune sensorineural hearing loss. Ann Otol Rhinol Laryngol 1979;88:585-589.

Merchant NS, Durand ML, Adams JC: Sudden deafness: is it viral? ORL J Otorhinoloaryngol Relat Spec 2008;70: $52-62$.

Nakashima T, Itoh A, Misawa H, Ohno Y: Clinicoepidemiologic features of sudden deafness diagnosed and treated at university hospitals in Japan. Otolaryngol Head Neck Surg 2000;123:593-597.

Psifidis AD, Psillas GK, Daniilidis J: Sudden sensorineural hearing loss: long-term follow-up results. Otolaryngol Head Neck Surg 2006;134:809-815.

Ren J, Li H, Lu Y: The determinations of tumor necrosis factor and interleukin 6 in serum of patients with sudden sensorineural hearing loss (in Chinese). Lin Chuang Er Bi Yan Hou Ke Za Zhi 1998;12:311-313.

Rudack C, Langer C, Junker R: Platelet GPIaC807T polymorphism is associated with negative outcome of sudden hearing loss. Hear Res 2004;191:41-48.

-Satoh H, Firestein GS, Billings PB, Harris JP, Keithley EM: Tumor necrosis factor-alpha, an initiator, and etanercept, an inhibitor of cochlear inflammation. Laryngoscope 2002;112:1627-1634.

-Satoh H, Firestein GS, Billings PB, Harris JP, Keithley EM: Proinflammatory cytokine expression in the endolymphatic sac during inner ear inflammation. J Assoc Res Otolaryngol 2003;4:139-147.

-Scherer EQ, Yang J, Canis M, Reimann K, Ivanov K, Diehl CD, et al: TNF $\alpha$ enhances microvascular tone and reduces blood flow in the cochlea via enhanced S1P signaling. Stroke 2010;41:2618-2624.

So HS, Kim HJ, Kim Y, Kim E, Pae HO, Chung HAT, et al: Evidence that cisplatin-induced auditory damage is attenuated by downregulation of proinflammatory cytokines via Nrf2/HO-1. J Assoc Res Otolaryngol 2008;9:290306.

-Solares CA, Tuohy VK: ELISPOT determination of interferon-gamma T-cell frequencies in patients with autoimmune sensorineural hearing loss. Methods Mol Biol 2005;302:253-260.

-Staecker H, Lefebvre PP: Autoimmune sensorineural hearing loss improved by tumor necrosis factor-alpha blockade: a case report. Acta Otolaryngol 2002;122:684-687.

-Suslu N, Yilmaz T, Gursel B: Utility of anti-HSP70, TNF $\alpha$, ERS, antinuclear antibody and antiphospholipid antibodies in the diagnosis and treatment of sudden sensorineural hearing loss. Laryngoscope 2009;119:341-346.

-Vambutas A, DeVoti J, Goldofsky E, Gordon M, Lesser M, Bonagura V: Alternate splicing of interleukin-1 receptor type II (IL1R2) in vitro correlates with clinical glucocorticoid responsiveness in patients with AIED. PLoS One 2009; 4:e5293.

Van Wijk F, Staecker H, Keithley E, Lefebvre PP: Local perfusion of the tumor necrosis factor a blocker Infliximab to the inner ear improves autoimmune neurosensory hearing loss. Audiol Neurotol 2006;11:357-365. 
Voronkin VF, Khanferian RA, Lazareva LA: Tumor necrosis factor as indicator of endogenic severity in acute neurosensory hypoacusis (in Russian). Vestn Otorhinolaryngol 1999;5:34-36.

Wakabayashi K, Fujioka M, Kanzaki S, Okano HJ, Shibata S, Yamashita D, Masuda M, Mihara M, Ohsugi Y: Blockade of interleukin-6 signaling suppressed cochlear inflammatory response and improved impairment in noisedamaged mice cochlea. Neurosci Res 2010;66:345-352.

-Yehudai D, Shoenfeld Y, Toubi E: The autoimmune characteristics of progressive or sudden sensorineural hearing loss. Autoimmunity 2006;39:153-158.

Yoshida K, Ischimiya I, Suzuki M, Mogi G: Effect of proinflammatory cytokines on cultured spiral ligament fibrocytes. Hear Res 1999;137:155-159.

Zou J, Pyykko I, Sutinen P, Toppila E: Vibration induced hearing loss in guinea pig cochlea: expression of TNF $\alpha$ and VEGF. Hear Res 2005;202:13-20. 